\title{
28 Research Square \\ Stroke Side Identification in the Brain by Retinal Image Analysis
}

\section{Yuanyuan Zhuo}

Shenzhen Traditional Chinese Medicine Hospital

Jiaye Lin

Chinese University of Hongkong

\section{Zhuoxin Yang}

Shenzhen Traditional Chinese Medicine Hospital

Haibo Yu

Shenzhen Traditional Chinese Medicine Hospital

Xingxian Huang

Shenzhen Traditional Chinese Medicine Hospital

Jack Lee

CUHK: The Chinese University of Hong Kong

\section{Benny Zee}

CUHK: The Chinese University of Hong Kong

Jiaman Wu ( $\nabla$ wujiaman202@163.com )

Affiliated Shenzhen Maternity and Child Healthcare Hospital https://orcid.org/0000-0001-9381-7711

\section{Research Article}

Keywords: retinal characteristics $\llbracket$ stroke side, retinal image analysis, biostatistics method, risk prediction.

Posted Date: July 26th, 2021

DOI: https://doi.org/10.21203/rs.3.rs-624118/v1

License: (c) (i) This work is licensed under a Creative Commons Attribution 4.0 International License.

Read Full License 


\section{Abstract}

Purpose To establish a prediction model for stroke side identification.

Methods A total of 168 patients (89 left-sided stroke patients and 79 right-sided stroke patients) were recruited from the Shenzhen Traditional Chinese Medicine Hospital in the study. Retinal characteristics were analyzed using an automated retinal image analysis (ARIA) system. Multivariable logistic regression was used to identify and develop predictive models.

Results Each unit increase in the right eye bifurcation coefficient of arterioles increased the risk of rightside stroke by 7.523 times $(95 \% \mathrm{Cl}, 1.823-31.044)$. Additionally, an elevated bifurcation coefficient of venules in the right eye also increased the risk of stroke in the right side of the brain, with an odds ratio (OR) of 7.377 (95\% Cl, 1.771-30.724). A complex retinal composite score was also associated with a higher risk of right-side stroke (OR, 4.955; 95\% Cl, 3.061-8.022).

Conclusion This study demonstrated that retinal image analysis can provide useful information for stroke side identification and the specific retinal characteristics may help in predicting stroke occurrence.

\section{Introduction}

Stroke has become the leading cause of death in China with an increased disease burden for the last 30 years. The rapidly aging population is one of the major reasons for this high prevalence.[1,2] Stroke is mainly classified into two types based on the clinical features: Ischemic, due to blood blockage, and hemorrhagic, due to burst bleeding. The location of stroke in the brain has a strong influence on the clinical consequences[3]. In most cases, stroke occurs only in one hemisphere of the brain and results in impairment on the opposite side of the body. Studies reveal that stroke in the left hemisphere affects motor control [4]as well as language and speech,[5] whereas right hemisphere stroke affects spatial orientation and posture.[4] Therefore, specific clinical advice and treatments are required for the patients depending on the stroke side.

Current techniques for stroke diagnosis have been well studied and accepted. Neurological examinations, such as the National Institutes of Health Stroke Scale (NIHSS) and Barthel index, provide information on the severity of stroke and activities of daily living, whereas imaging techniques such as Magnetic resonance imaging (MRI) and computed tomography (CT) assist in stroke diagnosis by identifying the locations and damages in the brain.(6) However, these techniques have some limitations, CT imaging exposes the patients to a high radiation dose while MRI is an expensive, time-consuming procedure.[6, 7] Therefore, there is a great need for new tools that can rapidly differentiate the damaged side of the brain after strokes at a relatively low cost.

The function of the retina makes it one of the most metabolically active tissues in the body and the double vascular network maintains its blood supply. A small part of the circulation can be observed directly through the retina.[8] Previous studies have shown that some characteristics of retinal 
microvasculature are associated with strokes, which may be predicted by computational retinal analysis[9-14]. Most studies have investigated the relationship between the risks of strokes and retinal characteristics, but the association between retinal parameters and the stroke side has not been demonstrated so far. In this study, retinal parameters were extracted from color fundus retinal images and the retinal characteristics were used via a logistic model to explore the association further.

\section{Materials And Methods}

\section{Data source}

Two hundred and fifty-four stroke patients from Shenzhen Traditional Chinese Medicine Hospital were enrolled in this study. Baseline data, including age, sex, medical history, physical examination, laboratory tests, NIHSS, and Barthel index were collected. All patients underwent a detailed cranial MRI scan.

All patients were diagnosed with either left or right hemispheric stroke, aged 30-80 years, with an adequate sitting balance to undergo retinal photography. Patients aged over 80 years were not included in the study because of much higher prevalence of age-related optical opacity and other comorbidities as compared to the younger patients, making them unsuitable for retinal photography and may have caused a bias. Patients with eye diseases influencing the retinal vasculature, and those who are physically or subjectively unable to comply with MRI scans were excluded. Furthermore, subjects suspected to have cerebral diseases and those with diseases influencing vessel morphology were also excluded. Ultimately, 168 of the 254 patients who presented with stroke were included in this study.

The clinical and radiological information of the patients along with the stroke side was evaluated and their association with retinal characteristics were analyzed.

\section{Retinal characteristics}

Retinal characteristics include retinal vessel measurements, arteriole-venous nicking, arteriole occlusion, tortuosity, hemorrhage, exudates, asymmetry of branches, bifurcation coefficients (BC), and bifurcation angles (BA). According to the formula developed by Knudtson(2003) et al., the retinal vessel measurements were summarized into central retinal artery equivalent (CRAE) and central retinal vein equivalent (CRVE), representing the diameters of arterioles and venules respectively.[15] The arteriole-tovenule ratio (AVR) was calculated as the ratio of CRAE to CRVE. Vessel tortuosity was assessed by visual grading of one fovea-centred and one disc-centred fundus image from each image. Arteriole-venous nicking results in narrowing of the venule when crossed by an arteriole, and arteriole occlusions referred to the blockage of blood flow inside the arterioles when obstructed by an emboli. The branching pattern of retinal vessels, such as Bifurcation coefficient (BC); the ratio of the widths of branching vessels to trunk vessels, bifurcation angle (BA); angle between two branching vessels and asymmetry; ratio of diameters of two branching vessels demonstrates the relationship between the trunk and the branching vessels. The fractal dimension (FD) of the retinal vasculature measured the complexity of branching 
patterns. The analysis was performed using three sets of vessels in one retinal image. Hemorrhages and exudates were recorded as present or absent and indicated in probability ( 0 to 1$)$.

\section{Statistical Analysis}

Descriptive statistics, chi-square tests, and two-tailed independent samples t-tests were used to compare the demographics and retinal characteristics between the left and right stroke sides. A p-value $<0.05$ was considered statistically significant. Odds ratios (ORs) and corresponding $95 \%$ confidence intervals ( $95 \%$ Cls) were obtained by logistic regression to control for confounding. Stepwise multivariable logistic regression was employed to select the best model. The classification accuracy and the area under the receiver operating characteristic $(\mathrm{ROC})$ curve were measured. Leave-one-out classification was used to validate the developed model. All the data was analyzed using SPSS 25.0 software (IBM, New York, USA).

The fully automatic retinal image analysis method was developed using R (University of Auckland, Auckland) and MATLAB (MathWorks, Massachusetts, USA) computer software. The detailed procedure of the automatic retinal imaging analysis can be found in Zee.[16]

\section{Results}

Descriptive demographic variables

In total, 168 patients (133 men and 35 women) with mean age of 55.72 years, 89 left-side strokes and 79 right-side strokes were analyzed in this study. Among these patients, $113(67.3 \%)$ had ischemic strokes and $50(29.8 \%)$ had hemorrhagic strokes. Smokers and drinkers in this analysis include both current and former status. A summary of the demographic variables is listed in Table 1. In general, there was no significant difference in demographics between the patients with stroke on the left side and the right side. 
Table 1

Demographic data of patients with stroke in the left and right sides

\begin{tabular}{|c|c|c|c|c|}
\hline & Total $(n=168)$ & Left side $(n=89)$ & Right Side $(n=79)$ & p-Value \\
\hline Male (n/\%) & $133(79.2 \%)$ & $70(78.7 \%)$ & $63(79.7 \%)$ & .862 \\
\hline Age $($ mean $\pm S D)$ & $55.72 \pm 10.89$ & $56.61 \pm 10.61$ & $54.72 \pm 11.18$ & .264 \\
\hline $\mathrm{BMI}($ mean $\pm \mathrm{SD})$ & $23.29 \pm 2.80$ & $23.27 \pm 2.69$ & $23.31 \pm 2.94$ & .930 \\
\hline Smoker (\%) & $50(29.7 \%)$ & $26(29.2 \%)$ & $24(30.4 \%)$ & .531 \\
\hline Drinker (\%) & $31(18.5 \%)$ & $15(16.8 \%)$ & $16(20.2 \%)$ & .845 \\
\hline Insomnia (\%) & $56(33.3 \%)$ & $28(32.2 \%)$ & $28(35.4 \%)$ & .926 \\
\hline Hypertension (\%) & $135(80.4 \%)$ & $73(83.9 \%)$ & $62(78.5 \%)$ & .370 \\
\hline Diabetes (\%) & $55(32.7 \%)$ & $27(30.3 \%)$ & $28(35.4 \%)$ & .481 \\
\hline \multicolumn{5}{|l|}{ Stroke Type } \\
\hline Ischemic (\%) & $113(67.3 \%)$ & $57(64.0 \%)$ & $56(70.9 \%)$ & \multirow[t]{3}{*}{.139} \\
\hline Haemorrhagic (\%) & $50(29.8 \%)$ & $31(34.8 \%)$ & $19(24.1 \%)$ & \\
\hline Both (\%) & $5(3.0 \%)$ & $1(1.1 \%)$ & $4(5.1 \%)$ & \\
\hline
\end{tabular}

Univariate analysis of retinal characteristics

Table 2 summarizes the retinal characteristics of the left and right eyes of the patients. From the results of univariate analysis, only venous asymmetry (Vasymmetry) in the left eye showed a slight but significant decrease in left-side stroke with an odds ratio (OR) of $1.227(95 \% \mathrm{Cl}, 1.053-1.431 ; P=0.009)$. However, for other retinal characteristics, there was no significant difference between left-side and rightside strokes in either the left or right eye. 
Table 2

Retinal characteristics among patients with stroke in different sides

\begin{tabular}{|c|c|c|c|c|c|c|}
\hline & \multicolumn{3}{|c|}{ Left Eye (Mean \pm SD) } & \multicolumn{3}{|c|}{ Right Eye (Mean \pm SD) } \\
\hline & $\begin{array}{l}\text { Left side ( } \mathrm{n} \\
=89 \text { ) }\end{array}$ & $\begin{array}{l}\text { Right side ( } \mathrm{n} \\
=79 \text { ) }\end{array}$ & $\begin{array}{l}\mathrm{p}- \\
\text { Value }\end{array}$ & $\begin{array}{l}\text { Left side }(\mathrm{n} \\
=89)\end{array}$ & $\begin{array}{l}\text { Right side ( } \mathrm{n} \\
=79)\end{array}$ & $\begin{array}{l}\mathrm{p}- \\
\text { Value }\end{array}$ \\
\hline CRAE & $14.41 \pm 1.68$ & $14.61 \pm 0.78$ & .371 & $13.96 \pm 0.58$ & $14.00 \pm 0.67$ & .653 \\
\hline CRVE & $20.86 \pm 2.32$ & $21.12 \pm 0.77$ & .406 & $20.78 \pm 0.68$ & $20.84 \pm 0.76$ & .580 \\
\hline AVR & $0.69 \pm 0.04$ & $0.69 \pm 0.02$ & .581 & $0.67 \pm 0.02$ & $0.67 \pm 0.02$ & .992 \\
\hline BCV & $2.04 \pm 7.21$ & $1.29 \pm 0.02$ & .660 & $1.34 \pm 0.13$ & $1.33 \pm 0.12$ & .613 \\
\hline BCA & $1.61 \pm 0.16$ & $1.64 \pm 0.07$ & .169 & $1.44 \pm 0.47$ & $1.51 \pm 0.41$ & .353 \\
\hline Venous Angle & $67.82 \pm 7.62$ & $68.53 \pm 2.13$ & .470 & $69.03 \pm 2.36$ & $69.01 \pm 2.29$ & .970 \\
\hline Artery Angle & $70.31 \pm 7.75$ & $71.49 \pm 1.49$ & .156 & $\begin{array}{l}59.68 \pm \\
25.45\end{array}$ & $62.57 \pm 22.20$ & .436 \\
\hline Vasymmetry & $0.76 \pm 0.06$ & $0.77 \pm 0.02$ & $.009 *$ & $0.78 \pm 0.03$ & $0.78 \pm 0.02$ & .392 \\
\hline Aasymmetry & $0.83 \pm 0.06$ & $0.83 \pm 0.01$ & .491 & $\begin{array}{l}11.46 \pm \\
24.76\end{array}$ & $8.60 \pm 21.83$ & .430 \\
\hline AVNicking & $0.31 \pm 0.07$ & $0.31 \pm 0.08$ & .932 & $0.27 \pm 0.08$ & $0.27 \pm 0.09$ & .697 \\
\hline Tortuosity & $0.39 \pm 0.14$ & $0.38 \pm 0.06$ & .520 & $0.36 \pm 0.06$ & $0.37 \pm 0.07$ & .298 \\
\hline Haemorrhage & $0.22 \pm 0.06$ & $0.22 \pm 0.06$ & .937 & $0.19 \pm 0.07$ & $0.20 \pm 0.07$ & .174 \\
\hline $\begin{array}{l}\text { Arteriole } \\
\text { occlusion }\end{array}$ & $0.09 \pm 0.04$ & $0.09 \pm 0.03$ & .414 & $0.14 \pm 0.13$ & $0.12 \pm 0.07$ & .174 \\
\hline FDa & $1.16 \pm 0.17$ & $1.18 \pm 0.01$ & .262 & $1.31 \pm 1.22$ & $1.18 \pm 0.01$ & .845 \\
\hline FDv & $1.18 \pm 0.10$ & $1.19 \pm 0.01$ & .632 & $2.52 \pm 11.33$ & $1.32 \pm 1.26$ & .544 \\
\hline \multicolumn{7}{|l|}{${ }^{*} \mathrm{p}-$ Value $<0.05$} \\
\hline $\begin{array}{l}\text { Abbreviations } \\
\text { Arteriole-to-ve } \\
\text { of arterioles; } \mathrm{F}\end{array}$ & $\begin{array}{l}\text { E, central r } \\
\text { liameter ra }\end{array}$ & artery equi & $\begin{array}{l}\text { CRV } \\
\text { effici }\end{array}$ & $\begin{array}{l}\text { ntral retin } \\
\text { f venules; }\end{array}$ & $\begin{array}{l}\text { equivalent; } \\
\text { ifurcation } \mathrm{C}\end{array}$ & $\begin{array}{l}\text { ent } \\
\text { ork. }\end{array}$ \\
\hline
\end{tabular}


Table 3

Multivariable logistic regression for stroke sides

\begin{tabular}{|lccc|}
\hline & OR & $95 \% \mathrm{Cl}$ & p-Value \\
\hline RBCA & 7.523 & $1.823-31.044$ & $.005^{*}$ \\
\hline RBCV & 7.377 & $1.771-30.724$ & $.006^{*}$ \\
\hline Retinal Composite Score & 4.955 & $3.061-8.022$ & $<.001^{*}$ \\
\hline *p-Value < 0.05. & & & \\
\hline $\begin{array}{l}\text { Abbreviations: RBCV, bifurcation coefficient of venules in the right eye; RBCA, bifurcation coefficient of } \\
\text { arterioles in the right eye. }\end{array}$ & & \\
\hline
\end{tabular}

Abbreviations: BCV: Bifurcation Coefficients of venular; BCADBifurcation Coefficients of arteriole; CRAE Central Retinal Artery Equivalent; CRVE囚 Central Retinal Vein Equivalent; AVR: Arteriole-to-venule Ratio; FDa, Fractal dimension of arteriolar network; FDv: Fractal dimension of venular network; Vasymmetry : Asymmetry index of venules Aasymmetry: Asymmetry index of arterioles;

Multivariable analysis of retinal characteristics

Using left-side stroke as the reference, the results from the multivariable logistic regression analysis of retinal characteristics are shown in Table 3. As shown in this table, two right-eye retinal characteristics and the retinal composite score were strongly associated with the stroke side. Patients with an increased bifurcation coefficient of arterioles in the right eye (RBCA) were at seven times higher risk of right-sided strokes, with an OR of $7.523(95 \% \mathrm{Cl}, 1.823-31.044 ; P=0.005)$. In addition, a higher value of bifurcation coefficient of venules in the right eye (RBCV) was also associated with a higher risk of right-side strokes, with an OR of $7.377(95 \% \mathrm{Cl}, 1.771-30.724 ; P=0.006)$. Furthermore, a retinal composite score including complex effects containing tortuosity, hemorrhage, and fractal dimension of the vessel network, were also positively associated with right-side stroke (OR, 4.955; 95\% Cl, 3.061-8.022; $P<0.001)$.

Abbreviations: RBCV, bifurcation coefficient of venules in the right eye; RBCA, bifurcation coefficient of arterioles in the right eye.

The area under the ROC curve was $0.842(95 \% \mathrm{Cl}, 0.782-0.901)$ for the multivariate logistic regression with a sensitivity of $79.8 \%$ and specificity of $73.4 \%$ using a cutoff of 0.5 probability, indicating an excellent potential predictive ability. (Fig. 1)

Validation.

The validation of the logistic model was performed via leave-one-out cross-validation. Using RBCA, RBCV, and retinal composite score, $76.2 \%$ of left-side strokes and $74.4 \%$ of right-side strokes were correctly classified with a total accuracy of $75.3 \%$. 


\section{Discussion}

Previous studies have revealed the association between retinal characteristics and stroke in many aspects[17-23], but here we further investigated the association of the brain side with stroke. It might be an effective way to reduce the burden by specifying the treatment according to the side of the stroke. Hence, identifying the stroke side was one of the critical roles. The current imaging tool and the gold standard would be MRI[24-26], but since it is an expensive and a time-consuming procedure, its use clinically and in research is limited. Other imaging tests, such as CT and angiography, help in identifying the location hours after strokes, but one of the problems using CT is the high radiation dose. Since the changes in retinal vessels can reflect some abnormalities in the cerebrovascular system, retinal characteristics might also provide information for diagnosis and treatment of brain diseases[27-29]. To our knowledge, no study has investigated the association between retinal characteristics and stroke sides. Therefore, this study is the first to demonstrate that the eyes on one side might not correspond to the same side of the brain, but the retinal characteristics of both the eyes together would be able to determine the side of stroke. We further established a prediction model that may provide an additional source for stroke side identification. The retinal characteristics provided a classification of the left and right stroke sides with $76.8 \%$ accuracy based on the current study.

Our study found that an increased bifurcation coefficient for arterioles and venules was associated with a higher risk of right-side stroke, which indicated changes in the branching pattern of retinal vessels. In normal conditions, the pattern of retinal vasculature would provide an optimal route for blood flow with minimal energy costs[30]. Although there is no literature available to support this finding, it might reflect that the side of the brain where the vessels are damaged by strokes could be identified via bifurcation coefficient in the retina. Since the biological effects are thought to be more complex, we explored the interactions between retinal characteristics. In this study, we found that as a series of retinal components increased $\triangle \mathrm{CRAE}, \mathrm{CRVE}, \mathrm{BCA}$, Venous Angle, Artery Angle, FDa囚at the same time, the risk of right-side stroke increased.

This study has several strengths and limitations. One of the major strengths of this study is that it is the first study to investigate the association between retinal characteristics and the stroke side and it also establishes a preliminary prediction model for identification. Some limitations should also be noted. First, the small sample size and missing values affect the statistical power of the model; for instance, exudate is a useful retinal parameter, but due to a large number of missing values, it cannot be presented in the model. In addition, a cross-sectional design makes it difficult for causal inferences. As a preliminary study, the underlying mechanisms for the associations are still unclear. In the future, we need to increase the sample size and design a better study model to investigate the issue. Moreover, to fulfill the need for clinical application, this model should also be validated.

\section{Conclusions}


This study provides an evidence of the association between retinal characteristics and stroke side. With the prediction model, in the future, we would be able to standardize the retinal image assessment automatically for the management of patients with stroke. This might be useful to improve the treatment and rehabilitation.

\section{Declarations}

Acknowledgements We would like to thank all the staff of the Shenzhen TCM Hospital for their support in our study. We would like to thank Editage [http://www.editage.com] for editing and reviewing this manuscript for English language.

Authors' contribution YY Zhuo and ZX Yang were involved in the study design. HB Yu and ZX Yang provided clinical assistance. $J$ Lee and $B$ Zee calculated retinal characteristics using the ARIA system. $J$ Lee was closely involved in data analysis and interpretation. XX Huang $₫ J Y$ Lin and YY Zhuo prepared the draft of the manuscript. ZX Yang and JM Wu revised the manuscript. All authors have read and approved the final manuscript.

Funding The National Natural Science Fund of China (81803952), National Key R\&D Program of China (2019YFC1712200). International standards research on clinical research and service of AcupunctureMoxibustion (2019YFC1712205) \the Shenzhen Municipal Science and Technology Bureau (JCYJ20170412174025934), Sanming Project of Medicine in Shenzhen (SZSM201612001).

Availability of data and materials All the data we collected were recorded in the in-patient department electro-medical recorder system. We collected the clinical risks factors and filled them in the Excel form. The EXCEL data used to support the findings of this study are available from the corresponding author upon request.

\section{Declarations}

Conflicts of Interest The authors declare that they have no competing interests.

Ethical Approval This study was approved by the Ethics Committee of the Shenzhen Traditional Chinese Medicine Hospital (approval number: 2018-75) and was performed in accordance with the guidelines of the Helsinki Declaration. All patients or their legal representatives provided written informed consent.

Clinical Trial Registry Chinese Clinical Trial Registry \ChiCTR1800019648囚Registered 1 September 2018, http://www.acmctr.org/usercenter.aspx

Consent to participate Informed consent was obtained from all patients included in the study.

Consent for publication Patients have consented to the usage of retinal images in this paper and the publication of this study. 
Open Access This article is licensed under a Creative Commons Attribution 4.0 International License, which permits use, sharing, adaptation, distribution and reproduction in any medium or format, as long as you give appropriate credit to the original author(s) and the source, provide a link to the Creative Commons licence, and indicate if changes were made. The images or other third party material in this article are included in the article's Creative Commons licence, unless indicated otherwise in a credit line to the material. If material is not included in the article's Creative Commons licence and your intended use is not permitted by statutory regulation or exceeds the permitted use, you will need to obtain permission directly from the copyright holder. To view a copy of this licence, visit http://creativecommons.org/licenses/by/4.0/.

\section{References}

1. Wang W, Jiang B, Sun H, Ru X, Sun D, Wang L, Wang L, Jiang Y, Li Y, Wang Y, Chen Z, Wu S, Zhang Y, Wang D, Wang Y, Feigin VL (2017) Prevalence, Incidence, and Mortality of Stroke in China: Results from a Nationwide Population-Based Survey of 480687 Adults. Circulation 135:759-771. http://10.1161/circulationaha.116.025250

2. Li Z, Jiang Y, Li H, Xian Y, Wang Y (2019) China's response to the rising stroke burden. Bmj 364:1879. .http://10.1136/bmj.l879

3. Altiparmak T, Nazliel B, Caglayan HB, Tokgoz N, Gurses AA, Ucar M (2021) Headache features of cerebellar ischemic strokes: Clinical and radiological-experiences of a single center. J Clin Neurosci 88:173-177. http://10.1016/j.jocn.2021.03.036

4. Moghaddam MZ A Comparative Study on the Function of Right and Left Hemisphere between Bipolar Patients and Normal Individuals

5. Gajardo-Vidal A, Lorca-Puls DL, Hope TMH, Parker Jones O, Seghier ML, Prejawa S, Crinion JT, Leff AP, Green DW, Price CJ (2018) How right hemisphere damage after stroke can impair speech comprehension. Brain 141:3389-3404. http://10.1093/brain/awy270

6. Dehkharghani S, Andre J (2017) Imaging Approaches to Stroke and Neurovascular Disease. Neurosurgery 80:681-700. http://10.1093/neuros/nyw108

7. Vymazal J, Rulseh AM, Keller J, Janouskova L (2012) Comparison of CT and MR imaging in ischemic stroke. Insights Imaging 3:619 -619 27. http://10.1007/s13244-012-0185-9

8. Abràmoff MD, Garvin MK, Sonka M (2010) Retinal imaging and image analysis. IEEE Rev Biomed Eng 3:169-208. http://10.1109/rbme.2010.2084567

9. Fallico M, Lotery A, Reibaldi M (2020) Retinal artery occlusion and risk of stroke. J Vasc Surg 72:1832-1833. http://10.1016/j.jvs.2020.02.053

10. Fallico M, Lotery AJ, Longo A, Avitabile T, Bonfiglio V, Russo A, Murabito P, Palmucci S, Pulvirenti A, Reibaldi M (2020) Risk of acute stroke in patients with retinal artery occlusion: a systematic review and meta-analysis. Eye (Lond) 34:683-689. http://10.1038/s41433-019-0576-y 
11. Shaikh IS, Elsamna ST, Zarbin MA, Bhagat N (2020) Assessing the risk of stroke development following retinal artery occlusion. J Stroke Cerebrovasc Dis 29:105002. .http://10.1016/j.jstrokecerebrovasdis.2020.105002

12. Zee BCY, Lee J, Mok VCT, Li Q, Yang Z (2016) Stroke risk assessment for the community by automatic retinal image analysis using fundus photograph

13. Wu HQ, Wu H, Shi LL, Yu LY, Wang LY, Chen YL, Geng JS, Shi J, Jiang K, Dong JC (2017) The association between retinal vasculature changes and stroke: a literature review and Meta-analysis. Int J Ophthalmol 10:109-114. http://10.18240/ijo.2017.01.18

14. Zhuo Y, Yu H, Yang Z, Zee B, Lee J, Kuang L (2017) Prediction Factors of Recurrent Stroke among Chinese Adults Using Retinal Vasculature Characteristics. J Stroke Cerebrovasc Dis 26:679-685. http://10.1016/j.jstrokecerebrovasdis.2017.01.020

15. Zhou JQ, Fu J, Li JP, Wang XZ, Wang WY, Zhao BW, Qi M (2020) Retinal vascular diameter changes assessed with a computer-assisted software after strabismus surgery. Int J Ophthalmol 13:620-624. http://10.18240/ijo.2020.04.14

16. Zee CY, Lee JW, Li EQ (2014) Method and device for retinal image analysis. US

17. Liu B, Hu Y, Ma G, Xiao Y, Zhang B, Liang Y, Zhong P, Zeng X, Lin Z, Kong H, Wu G, Du Z, Fang Y, Huang M, Wang L, Yang X, Yu H (2021) Reduced Retinal Microvascular Perfusion in Patients With Stroke Detected by Optical Coherence Tomography Angiography. Front Aging Neurosci 13:628336. http://10.3389/fnagi.2021.628336

18. Xiao YY, Wei WB, Wang YX, Lu AD, Chen SH, Song L, Wu SL (2020) Correlation of the history of stroke and the retinal artery occlusion: a nested case-control study. Int $\mathrm{J}$ Ophthalmol 13:431-437. http://10.18240/ijo.2020.03.10

19. Zhao L, Wang H, Yang X, Jiang B, Li H, Wang Y (2021) Multimodal Retinal Imaging for Detection of Ischemic Stroke. Front Aging Neurosci 13:615813. http://10.3389/fnagi.2021.615813

20. Ayrignac X, Zagroun C, Coget A, Azakri S, Menjot de Champfleur N, Montcriol AL, Labauge P, Mourand I, Ducros A, Daïen V, Arquizan C (2020) Acute retinal arterial ischaemia: silent brain infarcts prevalence and short-term recurrence. Eur J Neurol 27:2517-2522. http://10.1111/ene.14485

21. Rudilosso S, Mena L, Esteller D, Olivera M, Mengual JJ, Montull C, Castrillo L, Urra X, Gómez-Choco M (2021) Higher Cerebral Small Vessel Disease Burden in Patients with White Matter Recent Small Subcortical Infarcts. J Stroke Cerebrovasc Dis 30:105824.

http://10.1016/j.jstrokecerebrovasdis.2021.105824

22. Son J, Shin JY, Kim HD, Jung KH, Park KH, Park SJ (2020) Development and Validation of Deep Learning Models for Screening Multiple Abnormal Findings in Retinal Fundus Images. Ophthalmology 127:85-94. http://10.1016/j.ophtha.2019.05.029

23. Brugnara G, Neuberger U, Mahmutoglu MA, Foltyn M, Herweh C, Nagel S, Schönenberger S, Heiland S, Ulfert C, Ringleb PA, Bendszus M, Möhlenbruch MA, Pfaff JAR, Vollmuth P (2020) Multimodal Predictive Modeling of Endovascular Treatment Outcome for Acute Ischemic Stroke Using MachineLearning. Stroke 51:3541-3551. http://10.1161/strokeaha.120.030287 
24. Zwartbol MH, van der Kolk AG, Kuijf HJ, Witkamp TD, Ghaznawi R, Hendrikse J, Geerlings MI (2021) Intracranial vessel wall lesions on 7T MRI and MRI features of cerebral small vessel disease: The SMART-MR study. J Cereb Blood Flow Metab 41:1219-1228. http://10.1177/0271678x20958517

25. Jiang J, Huang X, Zhang Y, Deng W, Shen F, Liu J (2019) Total MRI burden of cerebral vessel disease correlates with the progression in patients with acute single small subcortical strokes. Brain Behav 9:e01173. .http://10.1002/brb3.1173

26. Shu L, Liang J, Xun W, Yang H, Lu T (2020) Prediction for the Total MRI Burden of Cerebral Small Vessel Disease With Retinal Microvascular Abnormalities in Ischemic Stroke/TIA Patients, Front Neurol. 11: 268.http://10.3389/fneur.2020.00268

27. Zhao Y, Yang B, Xu AD, Ruan YW, Xu Y, Hu HL, Tan ZF (2020) Retinal Microvascular Changes in Subtypes of Ischemic Stroke, Front Neurol. 11: 619554.http://10.3389/fneur.2020.619554

28. Zhuo YY, Wu JM, Kuang L, Qu YM, Zee B, Lee J, Yang ZX (2020) The Discriminative Efficacy of Retinal Characteristics on Two Traditional Chinese Syndromes in Association with Ischemic Stroke, Evid Based Complement Alternat Med. 2020: 6051831.http://10.1155/2020/6051831

29. Yuanyuan Z, Jiaman W, Yimin Q, Haibo Y, Weiqu Y, Zhuoxin Y (2020) Comparison of Prediction Models based on Risk Factors and Retinal Characteristics Associated with Recurrence One Year after Ischemic Stroke. J Stroke Cerebrovasc Dis 29:104581. http://10.1016/j.jstrokecerebrovasdis.2019.104581

30. Shinozuka K, Tajiri N, Ishikawa H, Tuazon JP, Lee JY, Sanberg PR, Zarriello S, Corey S, Kaneko Y, Borlongan CV (2020) Empathy in stroke rats is modulated by social settings. J Cereb Blood Flow Metab 40:1182-1192. http://10.1177/0271678x19867908

\section{Figures}




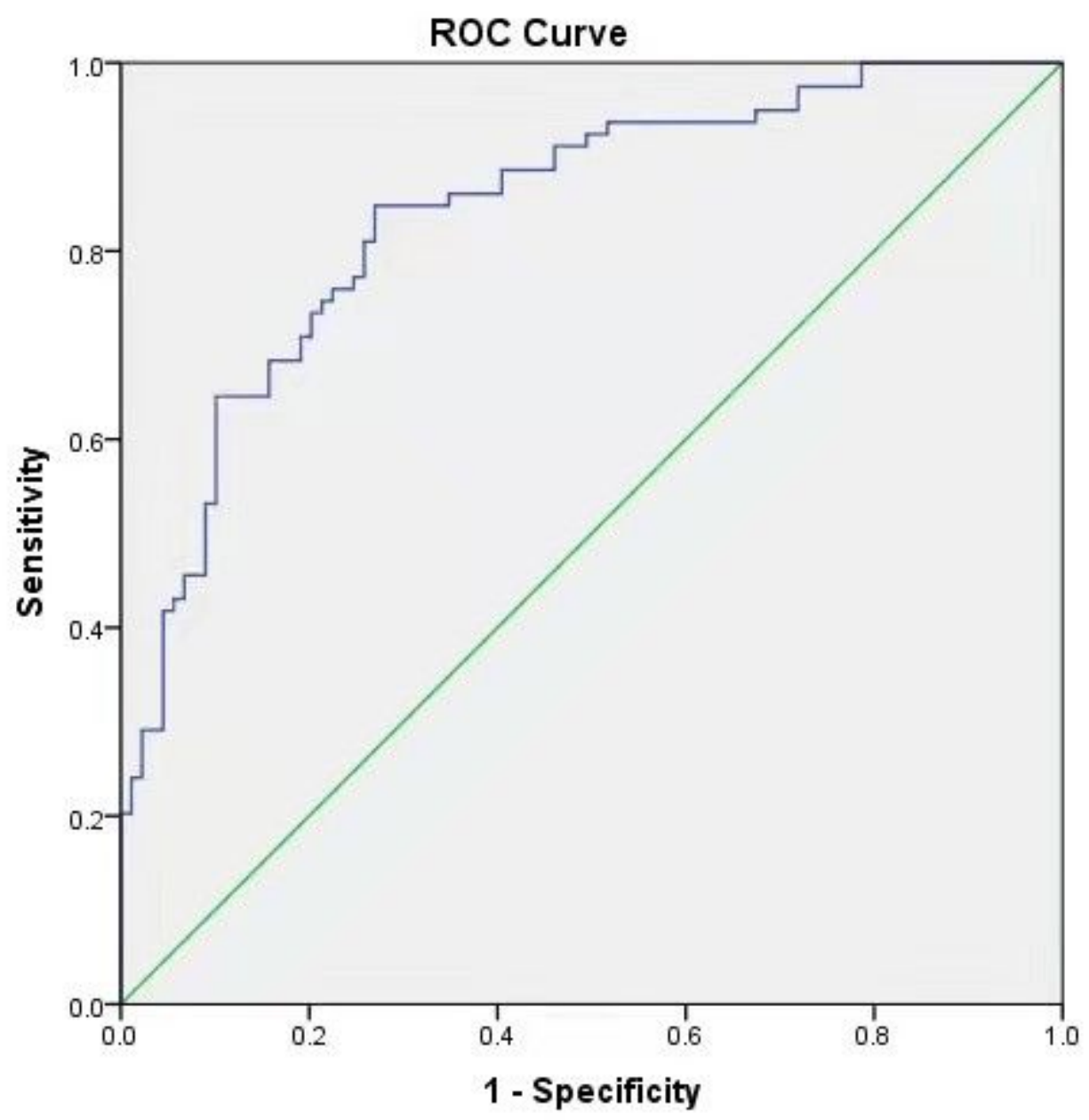

Figure 1

ROC curve of the multivariable logistic regression model for predicting stroke sides in patients.

\section{Supplementary Files}

This is a list of supplementary files associated with this preprint. Click to download.

- CONSORT2010Checklist.doc 